\title{
Enzyme activity and stability of lactase immobilized on two different supports: Calcium alginate and magnetic chitosan
}

\author{
Farah Syafiqah Mohd Zawawi a , Latiffah Karim a, ${ }^{*}$, Siti Radhiah Omar a, Asma’ Ali b \\ ${ }^{a}$ Fakulti Sains dan Teknologi, Universiti Sains Islam Malaysia, Bandar Baru Nilai, Nilai, 71800 Negeri Sembilan \\ ${ }^{b}$ Pusat pengajian Sains dan Teknologi Makanan, Universiti Malaysia Terengganu, 21300 Kuala Terengganu, Terengganu
}

* Corresponding author: latiffah16@usim.edu.my

\section{Article history}

Received 24 Mac 2020

Revised 12 May 2020

Accepted 30 June 2020

Published Online 16 August 2020

\begin{abstract}
Lactase is a very important enzyme to cure lactose intolerance problem. However, it is naturally existing in soluble form and cannot be reused. The current study was performed to compare the productivity and stability of lactase immobilized on calcium alginate and magnetic chitosan. The reusability of immobilized enzyme was measured for 28 days. Thermal stability was measured at $27,37,50$ and 70 ${ }^{\circ} \mathrm{C}$. Lactase immobilized on calcium alginate showed a better stability after 21 days where it retained up to $62 \%$ of enzyme activity. However, lactase on magnetic chitosan expresses a better thermal stability as it produced $6 \%$ more sugar than lactase on calcium alginate at the optimum temperature 50 ${ }^{\circ} \mathrm{C}$. Lactase immobilized on calcium alginate and magnetic chitosan showed significantly different enzymatic activity, stability, and reusability.
\end{abstract}

Keywords: Immobilized lactase, lactose, sodium alginate, magnetite, stability

C 2020 Penerbit UTM Press. All rights reserved

\section{INTRODUCTION}

Generally, lactase or $\beta$-galactosidase is well-known to have a major function in hydrolyzing lactose into glucose and galactose as depicted in Figure 1. The main disaccharide that exists in mammalian milks, lactose is quite unique compared to the other major dietary sugars because of the $\beta-1-4$ glycosidic linkage between its monosaccharides component which are glucose and galactose (Hertzler et al., 2017). While almost every mammalian especially human, need and will include milk in their diet to fulfill the nutrients need, the presence of excessive undigested lactose in the intestine can cause abdominal bloating, abdominal pain, vomiting, diarrhea, gas, nausea, and some other disturbing symptoms (Malik and Panuganti, 2019). Thus, lactase is a crucial enzyme in human digestive system to break down lactose into the simpler sugar hence allowing it to be absorbed in the small intestine, preventing lactose maldigestion and malabsorption.

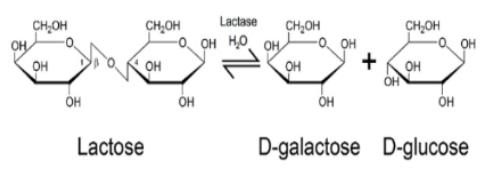

Figure 1 Hydrolysis of lactose into glucose and galactose by lactase enzyme (Leksmono et al., 2018).

Saqib et al. (2017) stated that lactases have high potential applications in food and pharmaceutical industry. Through hydrolytic activity, these enzymes are commonly applied in food industry in reducing the lactose content in food product, which can prevent the undesirable lactose crystallization, as well as improving the texture, flavor, sweetness, and the solubility of food and beverage products.
Besides, the process of treating lactose with lactase enzyme will break down lactose into glucose and galactose is beneficial as these two simple sugars will decrease the processing time in food products such as cottage cheese and yogurts because they can ferment more easily as compared to the disaccharide. Moreover, the need to use additional sweetener can also be decreased as the two simple sugars are sweeter than lactose, while at the same time lowering the number of calories in the final food products (Domingues et al., 2005).

On top of that, the complete hydrolysis of lactose into D-glucose and D-galactose can give the result of lactose-free products which are suitable for lactose-intolerant people (Silvério et al., 2018). It has also been used in pharmaceutical area to cure the ailment in many people whom affected by the lactose intake. People who are affected by this disorder should take additional lactase enzyme from outside of their body.

The importance of lactase enzyme in industry field is very big as it is useful to resolve the whey disposal problem on commercial scale (Karasova et al., 2002). In earlier times, whey was not being disposed properly and it has become a serious environmental issue. This was because the by-product of cheese industry was thrown directly into the water streams, and the acidity of water can kill marine living organism (Marwaha and Kennedy, 2007; Elnashar and Hassan, 2014). The usage of lactase enzyme to treat the whey will not only prevent water pollution but can also produce another useful product that can be further used in the industries such as ethanol or sweet syrup (Zhou and Chen, 2001). In a nutshell, due to the importance of lactase in our life and industry, the study on improving this enzyme's stability and reusability was conducted. 


\section{Immobilization of enzyme}

The method of immobilizing enzymes had been found almost a decade ago. It was first discovered by Nelson in his study about the adsorption of invertase in 1916. At first, the experiment was demonstrated to observe the invertase activity when it is adsorbed on a solid matrix and then it led to the development of many other enzyme immobilization techniques. Even though the study on enzyme immobilization has been started about hundred years ago, the ongoing investigations on this topic have proven that there is a continuous interest in this area. Ahmad and Sardar (2015) also stated that the earlier techniques used in enzyme immobilization resulted in a low enzyme loading due to the low surface area exposed to react with the substrate (Ahmad and Sardar 2015). However, the quality and application of recent immobilized enzyme has been improved and enhanced greatly. The previous studies have proven that the immobilized enzymes have increased in the resistance towards changes like $\mathrm{pH}$ and temperature. They are more stable and easier to be handled compare to the free form enzymes. They also allow the reaction to take place without contaminating the end products and this is very advantageous in the pharmaceutical and food industry. Nguyen and Kim (2017) added that immobilization technique give the ability for the enzyme to stop the reaction instantly by just removing and separating it from the reaction solution (Nguyen and Kim, 2017). Besides enhancing the enzyme properties, the immobilization of enzyme will also increase the rigidity of protein structure and preventing the inactivation caused by dissociation (Guzik et al.,2014; Rodrigues et al.,2013). On top of that, the immobilization method will enable the enzymes to be reused in the next reactions without the need to repeat the extraction and purification procedures which are quite costly and time consuming (Guzik and Wojcieszyńska,2014; Elnashar and Hassan, 2014). Thus, the usage of immobilized enzymes in industrial process is more conducive compared to the free enzyme since it provides the possibility of continuous flow process and low-cost operation (Elnashar and Hassan, 2014).

\section{Calcium alginate}

Alginate, the major structural polysaccharide of marine brown algae, is a gelling, stabling and thickening agent that can form heatstable gel in the presence of calcium. Calcium alginate gel was found to be able to immobilize enzymes, drugs, cells, and proteins (Mahajan, Gupta \& Sharma, 2010).

\section{Magnetic chitosan}

The application of magnetic particles has been found in various fields including enzyme immobilization, DNA separation, immunoassay, gene manipulation, and cell isolation (Chircov, et al., 2019). Despite the fact that there have been many trials made to utilize and optimize the immobilization methods (Fernandez-Lafuente, 2017; Gao et al., 2017), iron oxide particles provide a convenient, quick, and economical technique to immobilize the enzyme (Chien and Lee, 2008; Xie and Zang, 2016). Previous studies have proven that there are numerous advantages attained by using magnetic particles as carriers in enzyme immobilization. The fundamental benefits of magnetic particles are they provide a uniquely large surface area which solved the issue of limited enzyme loading capacity and they possess superparamagnetism which means that the particle will only be attracted by magnetic field but retain no residual magnetism after the field is removed and this allows the rapid and reliable separation from the reaction solution by easily applying an external magnetic field (Wang and Wang, 2009; Kazenwadel et al., 2015). Other than that, Wang et al. (2009) also revealed that the usage of magnetic particles would be beneficial as it offers versatile attachment protocols that can meet all type of enzymes. The small size of particles will increase the mass transfer of the substrate and the product, simultaneously increase the enzyme activity. Moreover, an immobilized enzyme with a gradually good stability can be produced with a proper coating of magnetic particles on the surface (Wang et al., 2009).

\section{EXPERIMENTAL}

\section{Materials}

Lactase and lactose were purchased from Nutricost and Lab-Ind Resource, respectively. Chitosan, glutaraldehyde, iron (II) chloride, iron (III) chloride, and calcium chloride were purchased from Sigma Aldrich. Sodium alginate and ammonium hydroxide were purchased from NacalaiTesquInc from Kyoto, Japan and Merck KGaA from Germany, respectively.

\section{Immobilizing lactase on calcium alginate}

In order to immobilize the enzyme, 2, 3, 4, and $5 \mathrm{~mL}$ of lactase was mixed with $20 \mathrm{~mL}$ of $2 \%(\mathrm{w} / \mathrm{v})$ sodium alginate solution. At the same time, $10 \%$ of calcium chloride solution was prepared. The homogenous solution of lactase and sodium alginate was then dropped carefully into the calcium chloride solution by using syringe and formed the immobilized lactase beads. Then, the beads were immersed in the solution for 30 minutes to allow the gelling process to occur completely. After that, the beads were washed with distilled water and then soaked in $0.1 \mathrm{M}$ acetate buffer $\mathrm{pH} 4.8$ for 30 minutes. The enzyme was stored at $4{ }^{\circ} \mathrm{C}$. This technique was accomplished by referring to the methods by Mandal et al. (2010) with some modifications.

\section{Synthesis of iron (II,III) oxide particles}

Firstly, iron (II,III) oxide which is also known as magnetite was synthesized according to the protocols shown by Radon et al. (2017). Next, $30 \mathrm{~mL}$ of distilled water was heated to $80^{\circ} \mathrm{C}$ and then $17.9746 \mathrm{~g}$ of iron (III) chloride salts were added and the solution was stirred for 10 minutes until the salts were completely dissolved. Simultaneously, $6.6182 \mathrm{~g}$ of iron (II) chloride was dissolved in distilled water until the salts were completely dissolved. Both solutions iron (II) and iron (III) were mixed at ratio $1: 2$ and then stirred for 10 minutes. Then, ammonium hydroxide was added dropwise into the mixture until the solution reached $\mathrm{pH}$ 9. Black precipitate was formed instantly indicating the formation of iron (II,III) oxide particles. The product was collected through magnetic decantation by using N50 neodymium magnet and the black precipitates were dried at $50{ }^{\circ} \mathrm{C}$ under vacuum overnight.

\section{Entrapment of magnetite with chitosan}

The magnetite was then undergone entrapment process with chitosan. The method was carried out by following the technique described by Popiskova and Safarik (2013) with some modifications. Chitosan $(1 \mathrm{~g})$ was dissolved in $50 \mathrm{~mL}$ of $0.2 \mathrm{M}$ acetic acid before $2 \mathrm{~g}$ of magnetite was added to the solution and mixed thoroughly. After that, an excess volume of sodium hydroxide was added and the solution was converted into magnetic chitosan gel. The chitosan gel with magnetite entrapped in it was washed with distilled water for several times and then ground into smaller particles by using standard kitchen blender. The suspension was then sieved and filtered.

\section{Cross linking and enzyme immobilization}

In this step, $0.3 \mathrm{~g}$ of magnetic chitosan particles was washed with distilled water and then put in $15 \mathrm{~mL}$ falcon tube. $4.5 \mathrm{~mL}$ of $5 \%(\mathrm{v} / \mathrm{v})$ glutaraldehyde solution was added and then incubated for 24 hours at 4 ${ }^{\circ} \mathrm{C}$ in incubator shaker (150 rpm) to modify the magnetic particles. After 24 hours, the glutaraldehyde solution was washed out and then the magnetic particles were carefully washed with distilled water. Consequently, $4.5 \mathrm{~mL}$ of enzyme in $0.1 \mathrm{M}$ phosphate buffer $\mathrm{pH} 7$ solution was added with different ratio $(0.5 \mathrm{~mL}$ lactase with $4 \mathrm{~mL}$ buffer, $1 \mathrm{~mL}$ lactase with $3.5 \mathrm{~mL}$ buffer, $1.5 \mathrm{~mL}$ lactase with $3 \mathrm{~mL}$ buffer, $2 \mathrm{~mL}$ lactase with $2.5 \mathrm{~mL}$ buffer) and then incubated for 24 hours at $4{ }^{\circ} \mathrm{C}$. After that, the supernatant with unbound enzyme was removed out and then the magnetic chitosan particles were washed with buffer.

\section{Enzyme activity}

In order to determine the catalytic performance of the immobilized lactase, lactose was controlled as substrate. Prior to analysis, $5 \mathrm{~g}$ of enzyme immobilized on calcium alginate beads was introduced in 10 $\mathrm{mL}$ of $1 \%(\mathrm{w} / \mathrm{v})$ lactose and let to react for 30 minutes at room 
temperature. After 30 minutes, $500 \mu \mathrm{L}$ of the product was collected and mixed with $250 \mu \mathrm{L}$ of $\mathrm{Na}_{2} \mathrm{CO}_{3} 1 \mathrm{M}$ to stop the reaction (Belhacene et al., 2015). Then, the glucose concentration in the product was measured by using blood glucose meter (BGM). The same protocol was used to determine the catalytic performance of enzyme immobilized on magnetic chitosan, except for the weight of enzyme used was $0.3 \mathrm{~g}$ and reacted with $5 \mathrm{~mL}$ of $1 \%(\mathrm{w} / \mathrm{v})$ lactose. The glucose level produced after lactose with same concentration was reacted with enzyme immobilized on calcium alginate and enzyme immobilized on magnetic particle were compared.

\section{Determination of enzyme stability and reusability}

The operation stability and reusability of immobilized enzyme was tested using the similar method as in determination of enzyme activity using lactose and it was done for 7 days straight, and once a week after, in 28 days. The hydrolases activity was measured for each cycle and it was determined and compared by taking the initial activity in the first cycle as $100 \%$. 100

Percentage activity $=$ glucose reading/glucose reading for day $1 \mathrm{X}$

The thermal stability of the immobilized lactase on calcium alginate and magnetic chitosan was also determined by reacting the enzyme and substrate at four different temperatures $\left(27,37,50\right.$, and $\left.70{ }^{\circ} \mathrm{C}\right)$.

\section{RESULTS AND DISCUSSION}

In this study, lactase was successfully immobilized on two different types of support which are calcium alginate beads and magnetic chitosan particles. The structure of the lactase enzyme right after immobilization process was observed and shown in Figure 3.1. There are some clear differences between the immobilized lactase on these two types of support.

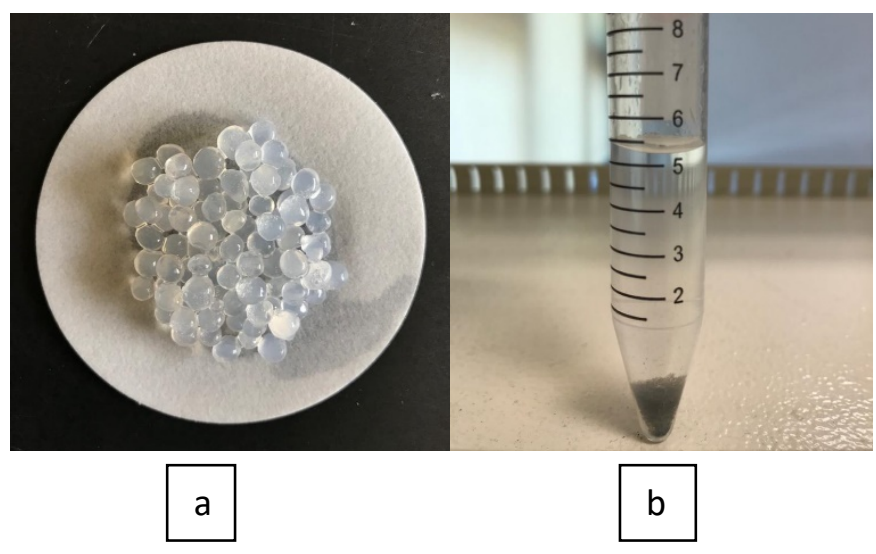

Figure 3.1 Lactase immobilized on a) calcium alginate beads and b) magnetic chitosan.

The first immobilization method was carried out by the entrapment of the enzyme by calcium alginate. Entrapment method is well known as one of the easiest techniques of enzyme immobilization (Mandal et al., 2010). In this study, many trials have been done by referring to the methods by Mandal et al. (2010) with modifications. The problems arose in choosing the suitable concentration of sodium alginate and calcium chloride solution as both of them affected the enzymatic activity of the enzyme when reacted with substrate. The polymer must be kept at appropriate rate as if it is too thick, it will cause low activity of enzyme (Vieira and Amaral, 2015). Generally, this method increases the stability of the enzyme and avoiding enzyme leaching and denaturation as the enzymes do not involve in chemical interaction with the polymers, instead, they are restricted within confined space formed by the gel polymers (Mohamad et al., 2015). The rigidity of the support also allows the reusability of the immobilized enzyme to react with substrate repeatedly. However, the enzyme immobilized by using this method is not suitable to be used in the industrial activity where it was done at high temperature since polymers are less stable at that condition. According to Xiong et al. (2018), the low stability of gel towards thermal can be clarified by three main aspects which are the breakage of cross-linker chains, the rupture of polymer chains and the hydrolysis of the polymer itself (Xiong et al., 2018).

Immobilization on magnetic particle on the other hand is achieved by the crosslink between the enzyme and the magnetic particles coated by chitosan which is done by the help of glutaraldehyde as the activating agent. The magnetic chitosan particles were modified by the glutaraldehyde first in order to attach with lactase enzyme. Only modified or fixed particles are able to attach with enzyme because of the free functional group available to bind with the functional group of the enzyme. In addition, the combination of these two supports provides a wide selection of functional group that can be used in protein attachment thus making the immobilization process more effective. Since the size of the magnetic chitosan particles are very small, this immobilization method provides an outstandingly large surface area of the immobilized enzyme thus solving the limited enzyme loading capacity issue (Kazenwadel et al., 2015). The substrate has higher chances to come in contact and reacted with the enzyme by using this method. The strong cross link force also allows the immobilized lactase to be used at high temperature.

\section{Effect of enzyme concentration}

Figure 3.2 shows the relationship between the amount of the lactase used and the glucose yield production. It is also shown that if the lactase amount is increased, the enzyme activity is also increased. From this figure, it is apparent that as more enzymes (lactase) are available to come in contact and react with the substrate (lactose), more products (glucose and galactose) are produced.

\section{Calcium alginate}

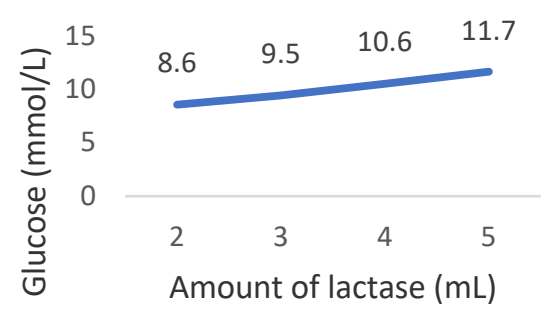

a) Sodium alginate

\section{Magnetic chitosan}

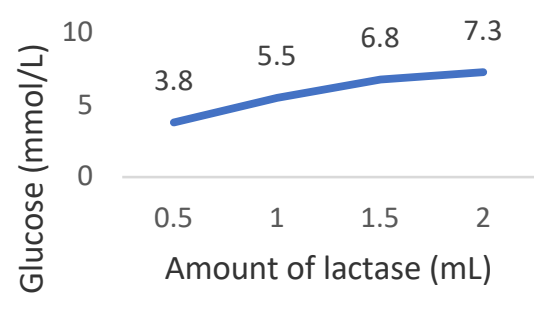

b) Magnetic chitosan

Figure 3.2 Effect of immobilized lactase using calcium alginate (a) and magnetic chitosan (b) on the amount of glucose production.

Based on the graph illustrated in Figure 3.2, it is shown that the increment of amount of lactase immobilized using calcium alginate gradually increase activity of the enzyme. This might due to the consistent entrapment method that can be achieved easily for four different amounts of enzymes immobilized on calcium alginate gel. However, four different concentrations of lactase immobilized on magnetic chitosan shown and increasing but inconsistent pattern of enzymatic activity even the quantity was increased uniformly. This might happen because the attachment of lactase enzyme to the support occurs unevenly in each process as the immobilization of lactase on magnetic chitosan is more prone to systematic error. This might be 
caused by different surface area of immobilized lactase exposed to the substrate during enzymatic reaction occurs. The results obtained shows that it behaves accordingly to the study by Eldin and Elaassar (2005) and Pan et al. (2009) where the enzyme activity is dependence on the amount of enzyme.

\section{Time stability}

In order to determine the operational stability of the immobilized lactase, it was reacted and reused repetitively for 7 days, and then reacted again after 14, 21, and 28 days. Comparing to the free enzyme, it can only be used for one time and cannot be recycled as it is dissolved in the substrate during the interaction process takes place. The results obtained proved that the immobilized enzyme can be reused until 28 days even though it shows some degeneration in the enzymatic activity.

Figure 3.3 and Figure 3.4 show the percentage of enzymatic activity of four different amount of lactase immobilized on calcium alginate and magnetic chitosan. The figures show that lactase immobilized on sodium alginate beads are more stable to be reused repeatedly compared to lactase immobilized on magnetic chitosan beads. The entrapment method by calcium alginate beads retain around 48 to $62 \%$ of enzyme activity after 28 days of reaction meanwhile the crosslinking between lactase and magnetic chitosan only maintain 16 to $27 \%$ when reacted at the same period of time.

These findings could be explained in two ways. The higher percentage activity of lactase immobilized on calcium alginate was achieved by few reasons as explained before. However, the rapid decline in percentage activity of lactase immobilized on magnetic chitosan possibly caused by the difficulty in controlling and maintaining the immobilized enzyme during the reaction process. This problem arose critically during removing the product out from enzyme and substrate mixture. The small particles of magnetic chitosan sometimes washed out together during the removal process of the products. The tiny size of enzyme does give benefit in providing higher surface area to come in contact with substrate but it is not suitable to be reacted with large volume of substrate. In addition, the small enzyme particle might contaminate the products if it is not collected and removed out properly after reaction.



Figure 3.3 Percentage of enzyme activity of lactase immobilized on calcium alginate beads for 28 days.

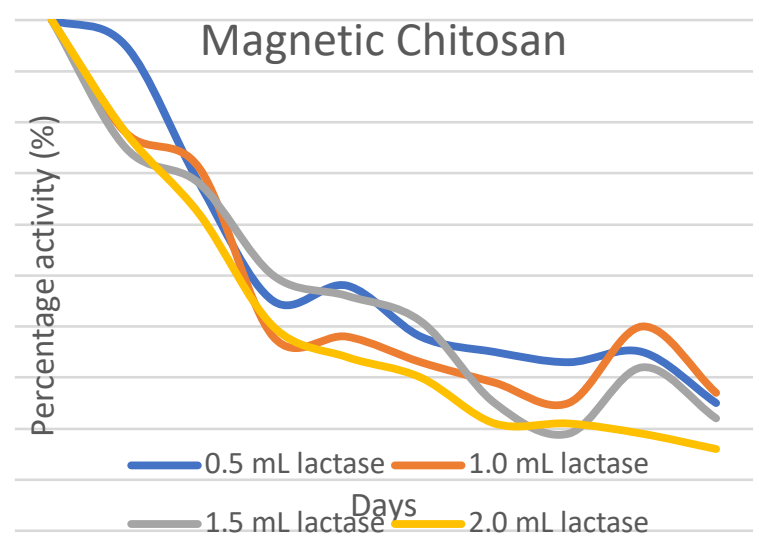

Figure 3.4 Percentage of enzyme activity of lactase immobilized on magnetic chitosan particles for 28 days.

\section{Thermal stability}

The enzymes were also examined at four different temperatures to determine their thermal stability. Figure 3.5 shows glucose reading when the immobilized lactase on calcium alginate and magnetic chitosan were reacted with lactose at four different temperatures which are $27^{\circ} \mathrm{C}, 37^{\circ} \mathrm{C}, 50{ }^{\circ} \mathrm{C}$, and $70^{\circ} \mathrm{C}$. The high glucose reading indicates that the enzymatic activity of the lactase is high.



$\longrightarrow$ Calcium alginate $\longrightarrow$ Magnetic chitosan

Figure 3.5 The effect of temperature on enzyme activity.

Based on Figure 3.5, the optimum temperature for the hydrolytic activity of both immobilized enzymes is at $50{ }^{\circ} \mathrm{C}$ where the glucose produced when lactose reacted with enzyme immobilized on calcium alginate and magnetic chitosan are $10.3 \mathrm{mmol} / \mathrm{L}$ and $16.7 \mathrm{mmol} / \mathrm{L}$, respectively. Based on the data collected, lactase immobilized on magnetic chitosan is proven to be less sensitive towards the heat compared to lactase immobilized on magnetic chitosan as it produced around $6 \%$ more sugar at the optimum temperature, and at all other tested temperatures.

These results could probably be related to the multiple binding sites between lactase and magnetic chitosan support which enhanced the stability of enzyme towards heat. The low stability of calcium alginate gel could be explained by breakage, rupture and hydrolysis of the polymer chain and the polymer itself (Eldin et al., 2012). Results obtained also show that increasing the temperature increase the reaction rate of the enzyme and substrate. However, due to the fragile structure of the enzyme, overheat can stimulate enzyme dissociation and resulting loss in enzymatic activity or inactivate the enzyme (Jurado et al., 2004). Based on the results, it can be concluded that lactase immobilized on magnetic chitosan is more suitable to be used in harsh temperature with lesser activity lost compared to lactase immobilized on calcium alginate beads. The immobilization enzyme on supports was proven can increase the stability of enzyme towards higher temperature compared to free enzyme (Mohamad et al., 2015).

\section{CONCLUSION}

In this study, the effect of two immobilized supports and methodologies on lactase enzyme was studied. The lactase was successfully immobilized on both techniques which are by entrapment with calcium alginate beads and by crosslinking with magnetic chitosan particles. Generally, lactase immobilized on calcium alginate and magnetic chitosan show significantly different enzymatic activity, stability, and reusability. It can be concluded that lactase immobilized on magnetic chitosan shows a higher activity and better stability towards heat but it is not suitable to be used for a long time of repetition. Lactase immobilized on calcium alginate on the other hand produces a lower enzymatic activity compared to magnetic chitosan lactase but it is more stable to be reused repeatedly with lower degradation in activity.

The immobilized lactase will attract the attention to be applied in industries as it can provide more effective, stable, and efficient enzyme and at the same time cost effective. It is recommended to look for or to produce a better support and technique for lactase immobilization which especially can retain most of the enzymatic activity, enhance the chemical, physical, mechanical and thermal stability of the lactase. 


\section{REFERENCES}

Ahmad, R., Sardar, M. 2015. Enzyme immobilization: an overview on nanoparticles as immobilization matrix. Biochemistry and Analytical Biochemistry, 4(2), pp. 1-8.

Belhacene, K. Grosu, E. F. Blaga, A. C. Dhulster, P. Pinteala, M. Froidevaux, R. 2015. Simple Eco-Friendly B-Galactosidase Immobilization on Functionalized Magnetic Particles for Lactose Hydrolysis. Environmental Engineering \& Management Journal (EEMJ), 14(3), pp. 1-8.

Chien, L. J. Lee, C. K. 2008. Biosilicification of dual-fusion enzyme immobilized on magnetic nanoparticle.Biotechnology Bioengineering, pp. 223-230.

Chircov, C., Grumezescu, A. M., Holban, A. M. (2019). Magnetic Particles for Advanced Molecular Diagnosis. Materials (Basel, Switzerland), 12(13), 2158.

Domingues, L., Lima, N., Teixeira, J. A. 2005.Aspergillusnigerbgalactosidase production by yeast in a continuous high cell density reactor. Process Biochemistry, 40(3-4), pp. 1151-1154.

Elnashar, M., Hassan, M. E. 2014. Novel epoxy activated hydrogels for solving lactose intolerance. BioMed Research International, 2014, pp. 1-10.

Eş, I. Vieira, J. D. G., Amaral, A. C. 2015. Principles, techniques, and applications of biocatalyst immobilization for industrial application. Applied Microbiology and Biotechnology, 99(5), pp. 2065-2082.

Eldin, M. S., El Enshasy, H. A., Hassan, M. E. 2012. Covalent immobilization of penicillin $G$ acylase onto chemically activated surface of PVC membranes for 6-APA production from penicillin hydrolysis process. IOptimization of Surface modification and its characterization. Journal of Applied Polymer Science, 124, pp. E27-E36.

Guzik, U., Hupert-Kocurek, K., Wojcieszyńska, D. (2014). Immobilization as a strategy for improving enzyme properties-application to oxidoreductases. Molecules (Basel, Switzerland), 19(7), 8995-9018.

Fernandez-Lafuente, R. (2017). Special Issue: Enzyme Immobilization 2016. Molecules (Basel, Switzerland), 22(4), 601.

Gao, J., Jiang, Y., Lu, J., Han, Z., Deng, J., Chen, Y. 2017. Dopaminefunctionalized mesoporous onion-like silica as a new matrix for immobilization of lipase Candida sp. Scientific reports, 7, pp. 99-125.

Haider, T., Husain, Q. 2007. Calcium alginate entrapped preparations of Aspergillusoryzae $\beta$ galactosidase: its stability and applications in the hydrolysis of lactose. International Journal of Biological Macromolecules, 41(1), pp. 72-80.

Hassan, M. E., Tamer, T. M., Ahmed, O. M. 2016. Methods of Enzyme Immobilization. International Journal of Current Pharmaceutical Review and Research, 7(6), pp. 385-392.

Hertzler, S., Savaiano, D. A., Dilk, A., Jackson, K. A., Bhriain, S. N., Suarez, F. L. 2017. Nutrient considerations in lactose intolerance.In Nutrition in the Prevention and Treatment of Disease. Academic Press, pp. 875-892.

Index 3.1.9. 2012. Cross-linking polymers-alginate worms [Online]. Accessed October 20, 2019 from https://scribd.com/document/101302786/3-1-9.

Jurado, E., Camacho, F., Luzón, G., Vicaria, J. M. 2004. Kinetic models of activity for $\beta$-galactosidases: influence of $\mathrm{pH}$, ionic concentration and temperature. Enzyme and Microbial Technology, 34(1), pp. 33-40.

Karasova, P., Spiwok, V., Mala, S., Kralova, B., Russell, N. J. 2002. Betagalactosidase activity in psychrophic microorganisms and their potential use in food industry. Czech Journal of Food Science, 20(2), pp. 43-47.

Kazenwadel, F., Wagner, H., Rapp, B. E., Franzreb, M. 2015.Optimization of enzyme immobilization microparticles using 1-ethyl-3-(3dimethylaminopropyl) carbodiimide (EDC) as a crosslinking agent. Analytical Methods, 7(24), pp. 10291-10298.

Leksmono, C. S., Manzoni, C., Tomkins, J. E., Lucchesi, W., Cottrell, G., Lewis, P. A. 2018.Measuring lactase enzymatic activity in the teaching lab. JoVE (Journal of Visualized Experiments), (138), pp. 54377.
Malik, T. F., Panuganti, K. K. 2019. Lactose intolerance. [Online]. Accessed November $\quad 18, \quad 2019 \quad$ from https://www.ncbi.nlm.nih.gov/books/NBK532285/

Mandal, S., Kumar, S. S., Krishnamoorthy, B., Basu, S. K. 2010. Development and evaluation of calcium alginate beads prepared by sequential and simultaneous methods. Brazilian Journal of Pharmaceutical Sciences, 46(4), pp. 785-793.

Mahajan, R., Gupta, V. K., Sharma, J. (2010). Comparison and suitability of gel matrix for entrapping higher content of enzymes for commercial applications. Indian Journal of Pharmaceutical Sciences, 72(2), 223-228.

Marwaha, S., Kennedy, J. 2007. Whey-pollution problem and potential utilization. International Journal of Food Science \& Technology, 23, pp. 323-336.

Nguyen, H. H., Kim, M. 2017. An overview of techniques in enzyme immobilization. Applied Science and Convergence Technology, 26(6), pp. 157-163.

Pan, C., Hu, B., Li, W., Sun, Y. I., Ye, H., Zeng, X. 2009. Novel and efficient method for immobilization and stabilization of $\beta$-d-galactosidase by covalent attachment onto magnetic Fe3O4-chitosan nanoparticles. Journal of Molecular Catalysis B: Enzymatic, 61(3-4), pp. 208-215.

Pospiskova, K. Safarik, I. 2013. Low-cost, easy-to-prepare magnetic chitosan microparticles for enzymes immobilization. Carbohydrate Polymers, 96(2), pp. 545-548.

Radon, A. Drygala, A. Hawalek, L. Lukowiec, D. 2017. Structure and optical properties of $\mathrm{Fe}_{3} \mathrm{O}_{4}$ nanoparticles synthesized by co-precipitation method with different organic modifiers. Material Characterization, 131, pp. 148156.

Rodrigues, R. C., Ortiz, C., Berenguer-Murcia, Á., Torres, R., FernándezLafuente, R. 2013. Modifying enzyme activity and selectivity by immobilization. Chemical Society Reviews, 42(15), pp. 6290-6307.

Saqib, S., Akram, A., Halim, S. A., Tassaduq, R. (2017). Sources of $\beta$ galactosidase and its applications in food industry. 3 Biotech, 7(1), 79.

Sheldon, R. A., van Pelt, S. 2013. Enzyme immobilisation in biocatalysis: Why, what and how. Chemical Society Reviews, 42(15), pp. 6223-6235.

Shen, Q., Yang, R., Hua, X., Ye F., Zhang, W., Zhao, W. 2011. Gelatintemplated biomimetic calcification for $\beta$-galactosidase immobilization. Process Biochemistry, 46, pp. 1565-1571.

Silvério, S. C., Macedo, E. A., Teixeira, J. A., Rodrigues, L. R. 2018. New $\beta$ galactosidase producers with potential for prebiotic synthesis. Bio resource Technology, 250, pp. 131-139.

Tian, X., Anming, W., Lifeng, H., Haifeng, L., Zhenming, C., Qiuyan, W., Xiaopu Y. 2009. Recent advance in the support and technology used in enzyme immobilization. African Journal of. Biotechnology, 8(19), pp. 4724-4733.

Wang, W., Li, Z., Wang, D. I. C. 2009.Immobilization of Enzymes on Functionalized Magnetic Nanoparticles for Efficient Biocatalysis. Technical Proceedings of the 2009 NSTI Nanotechnology Conference and Expo, NSTI-Nanotech, 2, pp. 337-339.

Xie, W. L., Zang, X. Z. 2016. Immobilized lipase on core-shell structured Fe3O4-MCM-41 nanocomposites as a magnetically recyclable biocatalyst for interesterification of soybean oil and lard. Food Chemistry, 194, pp. 1283-1292.

Xiong, C., Wei, F., Li, W., Liu, P., Wu, Y., Dai, M., Chen, J. 2018. Mechanism of polyacrylamide hydrogel instability on high-temperature conditions. ACS Omega, 3(9), pp. 10716-10724.

Zhou, Q. Z., Chen, X. D. 2001. Effects of temperature and pH on the catalytic activity of the immobilized b-galactosidase from Kluyveromyceslactis. Biochemical Engineering Journal, 9(1), pp. 33-40. 